\title{
Armament System of the Future Battlefield Being a Challenge for Security
}

\author{
Waldemar Krzton \\ Department of Security Science, Faculty of Management, Rzeszow University of Technology, Rzeszow, Poland
}

\section{Email address:}

wkrzton@prz.edu.pl

\section{To cite this article:}

Waldemar Krzton. Armament System of the Future Battlefield Being a Challenge for Security. Humanities and Social Sciences. Special Issue: Security Threats and Challenges of Modern World - Social and Cultural Dimension. Vol. 7, No. 5, 2019, pp. 159-163.

doi: $10.11648 /$ j.hss.20190705.13

Received: September 5, 2019; Accepted: September 25, 2019; Published: October 12, 2019

\begin{abstract}
The 21st century gave rise to numerous new processes in the development of war art. Some people call this phenomenon a technological revolution in the armed forces. Its essence lies in the emergence of new complex combat systems based on scientific achievements in the field of new technologies, computer science and electronics. The development of modern technology leads to new technical solutions and they change the nature of future armed conflicts and wars. Technology and war become even more complicated and the wars of the future will be complex and ambiguous. Those two kinds of development processes - technological development and war - depend on each other more than ever. The armed forces will use new technologies in armament. The new technologies will change future battlefield fundamentally and will allow soldiers to gain an advantage over the opponent as well as to decrease the risk significantly. New technologies used in conflicts will influence the future security. The aim of the article is to try to predict the use of state-of-the-art weaponry on the future battlefield, based on scientific achievements in the field of state-of-the-art technologies, computer science and electronics. It is synthetic, it is a proposal to look at future armament of potential armed conflicts and war.
\end{abstract}

Keywords: Security, Defence, Armed Conflict, War, Armament, Armed Forces

\section{Introduction}

An important factor influencing the development of the art of war are the means of combat, first of all, weapons, used as tools designed to destroy the enemy, eliminate his soldiers, equipment and fortifications. The development of weapons has been and is a fundamental indicator of changes in the art of war at the tactical, operational and strategic level.

Opposing parties use various weapons and equipment to conduct military actions. Today, systems of combat, support and security are equipped with specific means of combat, using state-of-the-art inventions in the fields of nanotechnology, computer science, automation and robotics. This resulted in the introduction of equipment with exceptional accuracy and reliability to the armament. Speaking of current weapons, the Tofflers state that "some of the key parameters of the wars that have been conducted so far have reached their final limit: range, lethal rate, speed" [1]. You still need to add accuracy.

The development of modern technology leads to new technical solutions and they change the nature of future armed conflicts and war. The use of innovative technologies has led to a phenomenon called 'war at a distance'. This term means the process of gradual "withdrawal" of soldiers from the battlefield, which leads to a reduction in personal losses. It is already also possible to command warfare from places far away from the battlefield. That is why people around the world can watch war using media, and war "becomes a remotely controlled spectacle" [2].

The essence of modern wars is cultural and religious violence directed at the transformation of "people's hearts and minds". Future wars will be different. Their goal will be primarily political domination, they will be conducted discreetly. It will be dominated by those who gain information advantage and use state-of-the-art weapons systems. It is technical progress and destructiveness that will determine victory. It is not occupying a specific area or having a large number of regular troops or using powerful explosives that will decide about victory, but controlling computers and networks and using devastating technologies. 
New war technologies allow armed forces to take advantage over their opponents and reduce risk on the battlefield. However, there is a great danger of untwisting the arms race spiral, which will be at stake to gain an advantage in the area of future technology.

\section{Future Battlefield}

Scientists at the U.S. Land Army Research Laboratory described the battlefield in 2050. They predict that: (1) it will be characterized by the presence of reinforced and improved people, (2) robots operating in groups and teams including people will be ubiquitous, (3) there will be automation of decision-making and process autonomy, both as for weapons and institutional systems used to command and control them, (4) large-scale self-organisation and community of the decision-making process of objects on the battlefield will dominate, (5) it will be common to model and simulate opponent's behaviour, (6) there will be a fierce battle in the information environment involving impersonation, hacking, misinformation and intense electronic warfare, (7) laser and microwave weapons will prevail in the weapons system, and attacks on specific individuals identified by the their unique electronic and behavioral signatures [3].

In the future, the soldier leading the fight will be part of the network connected to computers, his physical health or his mind will be monitored. The computer will estimate the state of weapons and ammunition, calculate its contribution to the combat achievements of the subdivision, and will give them orders. The technique will provide a soldier with far better information about the situation in the area of the task as well as more protection and more endurance. The organism of the soldiers will be modified in order to increase its efficiency. The bodies of soldiers will be artificially improved with: (1) exoskeletons - to increase their strength, (2) pharmacological agents - to improve memory and improve cognitive abilities; (3) surgery — to help the nervous system by implantation of microelectronic agents.

The armed forces of most countries of the world place great emphasis on the use of unmanned systems in combat operations. Unmanned, autonomous and controlled systems will be able to allow soldiers to act beyond the scope of the enemy's defensive measures and bind them from a safe distance.

Automatons will lead the fight at ever greater distances. Weapons systems will allow to carry out attacks over long distances. The missiles will not be fired in the direction of a specific object, but will be directed to where the target will be in the future. Modern systems will be able to control the areas where the potential target of the attack may be located and respond to the threat.

The war of the future will be conducted using computer networks. Computers will support soldiers and weapons on the battlefield and will be used to wage war in cyberspace. Artificial intelligence systems will analyze information provided by data from soldier's clothing, equipment and biometric sensors. Simulation and verification of combat activities will be presented to commanders along with a list of use of state-of-the-art weapons. Command, management and control will be linked, prioritized and centralised.

The battles will be conducted quickly, through the use of laser weapons and systems operating at the speed of light, the use of weapons and hypersonic vehicles. Time will be very valuable, and the speed of battles will put pressure on prompt decision making.

Conflicts and wars will be long in space and time, the opponent will not be easy to recognize. Fights may last for a long time, but they can also be violent and devastating as well as appear unnoticed or at incredible speed. Conflicts will be hybrid, i.e. nations, social groups, individuals will apply various forms of violence against other nations, groups and individuals. They will take the form of information operations, cyber-attacks, terrorism, conventional attacks and various forms of aggression.

The future battlefield will be scattered, action will be led by subtroops consisting of specialized professional soldiers, humans or robots. Clashes will be global, including space.

\section{Future War Weaponry}

It is technology that will decide about military superiority and domination on the future battlefield. Technology, in development of which the advances of information technology and robotics, cyber technologies, autonomous systems, destructive weapons and weaponry achieving incredible speeds will innovatively be used. In the United States armed forces, five areas of technology are identified, the development of which will give a strategic advantage when conducting operations on the future battlefield [4]. These are: (1) autonomous learning systems, or machines that can adapt to circumstances and learn over time, (2) human and machine collaboration, where machines help people process huge amounts of information, (3) support for operations fulfilled by human, such as sensors worn and communication equipment intended for soldiers on the battlefield, (4) military teams consisting of humans and machines in which manned armament interacts with the unmanned, which is responsible for providing information, communication and additional armament, (5) Semiautonomous networked technologies that allow armament elements to communicate with each other in order to search for targets in case the means of communication or connection of the sensor to the people responsible for making decisions are destroyed [3].

Military rivalry between the armies of individual states contributes most often to the modernization of used weapons. Currently, new weapons systems are being developed at the stage of predicting future potential conflicts.

\subsection{Geophysical Weapons}

Technical means are already being used to trigger various weather anomalies in certain areas. Planned use of nature for destructive effects on the environment is referred to as geophysical weapons. Weather changes can be used in the art 
of war. Selected critical infrastructure items may be damaged or destroyed by floods after heavy rains have been triggered. Similarly, using the same instruments (weapons) but in the opposite way as a consequence of the caused drought, specific damage or the occurrence of a permanent water deficit can be brought about. In turn, long-term snowfall, combined with a low temperature, can disrupt and even prevent communication and transport in selected areas.

It is quite possible that the use of geophysical weapons could significantly impede the proper functioning of the economy, industry and agriculture. As a result of these actions, it could be possible to gain an advantage and subdue another country without the need for military action [5].

The concept of using strong and accumulated ultra-high frequency waves to heat selected fragments of the atmosphere is the essence of the operation of geophysical weapons. This boils down to the deformation of the heated layer of the atmosphere. Such a heated atmosphere can be changed, that is, hover, unbend, build powerful electromagnetic lenses that will focus the sun's rays at fixed points (may cause drought). The use of such weapons can cause various kinds of cataclysms. Due to the fact that the emission pulse lasts a very short time and is imperceptible to the eye, the subject under attack is not aware of the weather attack. The catastrophes resulting from these weapons do not cause suspicion, they appear to be the action of the forces of nature [6].

The program of military research to understand, simulate and control processes in the ionosphere is the American HAARP project (High Frequency Active Auroral Research Program). Officially, the subject of research is phenomena which may affect the operation of electronic communication and supervision. However, the HAARP is a military project which makes the research conducted implicit. Therefore, many opinions have suggested that HAARP creates geophysical weapons that can cause earthquakes, cyclones, tsunamis as well as meteorological weapons capable of causing weather anomalies: floods, droughts and heavy snowfall. The radiation power of a special antenna installation, covering an area of approximately 24 hectares, allows the construction of electromagnetic weapons capable of accumulating energy in a small area. It also has the strength and instruments to build a psychotronic weapon that controls people's thoughts. These suspicions of HAARP's activities are based on the publication of numerous research results and predictions for future new combat and war systems [7].

The next example of a miracle weapon is the Russian Ionosphere Insulation Plant Sura, engaged in the study of the ionosphere. The Russians presented interesting research results on the behaviour of the ionosphere, namely, the effect of producing low-frequency radiation at the time of modulating ionospheric currents (Hetmantsev effect) was discovered [8]. By generating appropriate impulses, it is possible in properly selected technical parameters to lead to mistuning of electronic systems of artificial satellites, elimination of terrestrial electronic systems and other apparatus from operation. Ionosphere research is the beginning for the development of weapons capable of destroying by means of radio waves communication devices, precipitation of satellites and aircraft.

\subsection{Weapons of Directed Energy}

Weapons of directed energy are new armament systems in the field of electromagnetic weapons which use an electromagnetic pulse that triggers high voltage in networks and electrical and electronic devices. A rapid voltage surge leads to a sharp increase in the intensity of the electric current and an increase in temperature. The result is the release of large amounts of heat, which leads to damage to electronic circuits, electrical elements and transmission lines. This phenomenon is applicable to new weapons systems using directed energy. These weapons are electromagnetic guns, laser systems and microwave weapons. It is used to quickly neutralize the opponent, perform the task with the least human losses.

Pulse electromagnetic guns, laser systems and microwave weapons as weapons systems using directed energy, are the sphere of interest of the armed forces of many countries.

\subsection{Microwave Weapons}

Microwave weapons work for a specific purpose with electromagnetic radiation. Microwaves are radio waves, which is important from a military point of view because most of the radar operates in the range of microwave radiation. The action of the weapon is based on the emission of a highly concentrated stream of microwaves, which destroys electronic systems. Microwave weapons do not require ammunition, which makes it economical. This armament is effective because the electromagnetic flux cannot be deceived or disposed of. The new weapon also affects the human being causing the feeling of burning. Microwaves penetrate uniforms, combat suits and clothes quickly heating the surface of the skin. The possibility of damage to vision is not ruled out. As a result, people treated with microwaves do not function properly and should be withdrawn from the weapon's impact zone.

\subsection{Laser Weapons}

In the colloquial sense, the laser is a device that generates light by forcing emissions. The name of the laser device is an abbreviation of the English name Light Amplification by Stimulated Emission of Radiation. Since the 1970s laser weapons have been tested in various technical combinations. In the course of research, scientists decided that the technology at that time would not ensure the construction of lasers that could destroy certain specific targets. However, studies and tests have not been discontinued. In the 1980s, laser target tracking systems began to dominate the armament of most armies.

The next stage of technical development was the use of this technology to dazzle the opponent. In 2014, the first laser laser to be used in combat conditions was installed on board 
an American ship [9]. Laser weapons from the design and testing stage have become a reality, it is practically already possible to "shoot a laser" for the opponent's targets, and the range of laser action is twice as large as the range of classical guns.

In 2015, the Chinese presented PY132A laser rifles, designed to dismantle sensors and cameras, and could damage vehicles and drones. Laser weapon is also used by Israel to build a multi-element anti-aircraft defense system. Iron Beam will be an element used in the Iron Dome system of Israel's air defense. The basis of the Iron Beam system is a high-power laser and precise targeting device. The system fights artillery, rocket missiles, drones and other selected ground targets [10].

Marek Wrzosek believes that laser weapons have many important operational and technical attributes: (1) it does not require ammunition, so you do not need warehouses (warehouses, packaging) to store it. Therefore, all logistic issues can be abandoned - transport, replacement supplement; (2) only energy is needed to shoot laser weapons (3) operating costs. Standard artillery missiles or missiles reach prices comparable to the value of combat vehicles. Meanwhile, "laser ammunition" costs as much as the price of energy consumed to "shoot" [6].

A very important factor is the effectiveness of destruction of objects. The accuracy of the laser is due to the fact that it is a light resistant to wind, pressure or ballistics. Laser weapons are relatively cheap, accurate and effective.

The dream of soldiers is to have a reliable and fast-firing weapon, the action of which the opponent can notice only at the moment of hitting the target. Laser weaponry is sometimes seen as a universal weapon that works instantly and effectively. Because: (1) the flight speed of any projectile and its impact on targets occurs much later than the laser "projectile", (2) the high speed of light enables any projectile to be intercepted in flight [11].

\subsection{Sound Weapon}

A sound weapon is a device that emits sound waves of specific lengths causing specific reactions. Another notion that this weapon is often referred to is acoustic weapons or sonic weapons. The effect of this weapon is based on the use of specific sound frequencies, which cause vibration of elements of objects of influence [12].

Acoustic weapons use sound waves that are inaudible to humans due to very low frequency - infrasound, as well as ultrasound, high-frequency waves also inaudible by humans. Infrasound negatively affects the human body, disrupting the work of the heart and brain. In turn, ultrasound causes nagging symptoms in human, inducing headaches, nausea, anxiety or muscle spasms [13].

Long-term effect of sound waves of different frequencies emitted with adequate energy towards humans causes strong vibrations in their organisms. These vibrations can after some time damage the most important internal organs, cause loss of concentration and visual impairment. As a result of the influence of sound waves, a person will not be able to realize the tasks entrusted to him. The effectiveness of the action will depend on the intensity of the emitted sounds causing hearing loss, rupture of internal organs.

A next-generation energy-directed weapon using microwave, laser and sound technology is known and applied in the weapon systems of the future battlefield. The use of these weapons which instantly incapacitate command and control systems, ICT systems, navigation systems allows you to win the war without direct loss of human beings and without total destruction of infrastructure.

\subsection{Precision Weapons}

The development of military technology and technology promotes the production of increasingly dangerous and more accurate conventional weapons. The more accurate weaponry is constructed, the less you need to use ammunition, missiles, missiles or bombs to achieve your goals.

According to Łukasz Kamieński, during World War II, an average of 650 bombs had to be dropped in order to destroy a specific target, while only 300 during the Vietnam War. Data on the Iraq war indicate that only 1-2 "smart bombs" were enough, which reduces incidental damages and costs [3].

Fighting moving targets is and has always been a considerable challenge, therefore, precise weaponry has the ability to independently change the coordinates of an attack object changing its position. Nowadays, man-guided missiles are being abandoned, and weapons are beginning to have the advantage of looking for a potential opponent. The major way of guidance is by GPS. When the coordinates of the target have been entered, an intelligent weapon targets itself in its direction. It knows its location and knows where to go [14]. Such features allow you to conduct accurate strokes, achieve assumed effects and minimize adverse effects. The use of such precise weapons is aimed at the rapid, accurate destruction of specific targets, minimizing unplanned damage primarily to civilians. 'Surgical' strikes are most often airborne lightning operations that allow forces to achieve their targets with minimal confrontation with enemy troops.

\section{Automation of War}

The future battlefield will be dominated by a variety of types of automatons. In many modern armed forces, automated systems of command and control of means of destruction are standard [15]. The apparatus used in combat is not a model or a prototype, but the actual means of combat used by armies in dangerous areas. Nowadays, unmanned apparatus is already functioning in all areas and in all atmospheric conditions. Automatons appear before the soldiers are sent to the area of the operation. These machines independently exchange information and perform the tasks set before them. They take over the essential duties of the existing soldiers. In many cases, reconnaissance, protection or defence are carried out with the use of armed and homing unmanned devices [16].

Based on years of experience in the field of state-of-the-art technology, American scholars presented a futuristic vision of 
a future battlefield where soldiers and commanders are supported by advanced automatic systems in combat: "Instead of simple guided missiles or remote-controlled vehicles, we can introduce fully autonomous land, sea and air vehicles capable of carrying out complex reconnaissance and combat missions with a wide range [...]. The use of this new technology will allow machines to perform complex tasks with little human intervention or even fully independently [...]. The possibilities are so astonishing that they can significantly change the nature of armed conflicts" [17].

Artificial intelligence plays an essential role in the automation process. In laboratories around the world, engineers are developing and improving artificial intelligence at an express pace. The results of the development of this area of science give surprising results. During the information and cyber revolution, automatic vehicles without a driver are already operating, computers are controlling many areas of our lives, printers are used to print (produce) weapons and copy human organs. Experts of the topic estimate that in the middle of the 21 st century automatons will be present in almost all areas of human life. It is possible that in the near future people will be replaced by robots and they will become soldiers as well. Work is already being carried out on control with the use of neural links, weapons systems with the help of thought. That is, firing, striking opponent's targets, precise missile guidance is carried out with the help of devices, but through the thought of the operator.

\section{Summary}

In the 21 st century has changed its face, leading to the fact that future conflicts will be qualitatively and quantitatively different from those known in the past. It is assumed that they will be conducted using modern and special weapons.

The directions of development of weapons systems, military equipment, combat and materials are the result of many conditions. Among other things, the need for the armed forces and the need to resist new threats, especially military ones, play a fundamental role.

The predictable nature of the future battlefield determines the increased demand for precise systems for identifying threats for future actions. The development of technology increases the equipping of the armed forces with electronic means of combat. It can be assumed with a high degree of probability that the prerequisite for obtaining military superiority will be mastering the electromagnetic space, which will provide information advantage. Technical increase in fire capabilities is achieved by introducing new armament patterns to army equipment with better tactical and technical parameters, supported by modernized ammunition.

The development of combat measures is moving towards the maximum possible reduction of human role, replacing it with specialized devices (new weapons, unmanned platforms, battlefield robots).

The robotization of the armed forces raises genuine concern. Some scientists warn that the use of fully artificial intelligence for the needs of the military can lead to human extermination. People are limited, among other things, by evolution or biological processes, therefore, they may not be able to compete with the "a machine - a system, an automaton" and will be displaced from the decision-making process.

\section{References}

[1] A. H. Toffler, "War and Anti-War," MUZA SA, Warsaw 1997, p. 44 .

[2] L. Kamienski, "Technology and the Future of War. On Nuclear and Information Revolutions in Military Affairs," Jagiellonian University Publishing House, Krakow 2009, pp. 238,233 .

[3] R. H. Latiff, "Future War: Preparing for the New Global Battlefield," PWN, Warsaw 2018, pp. 30-31, 36-37.

[4] D. Ignatius, "Arming Ourselves for the Next War", Washington Post, February 24, 2016.

[5] W. Kaczmarek, Z. Scibiorek, “Przyszła wojna-jaka?”, BUWiK, Warsaw 1995, p. 35.

[6] M. Wrzosek, "Wojny przyszłości. Doktryna, technika, operacje militarne", Fronda, Warsaw 2018, pp. 117, 129-130.

[7] J. Smith, "HAARP: The Ultimate Weapon of the Conspiracy," Amber, Warsaw 2004, p. 29.

[8] http://www.iluminaci.pl/haarp/sura-i-haarp.

[9] https://tylkonauka.pl/wiadomosc/pierwsze-na-swiecie-dzialolaserowe-gotowe-do-uzycia.

[10] https://www.defence24.pl/laserowy-system-obronypowietrznej-izrael-wdraza-zelazny-promien-video.

[11] Z. Mierczyk (ed.), "Nowoczesne technologie systemów uzbrojenia", WAT Warsaw 2008, p. 449.

[12] P. Swarts, "Air Force Looking at Autonomous Systems to Aid War Fighters", Air Force Times, May 17, 2016.

[13] G. R. Lucas, "Military Ethics: What Everyone Needs to Know", Oxford University Press, New York 2016, p. 17.

[14] M. Libick, "The Emerging Primacy of Information", Orbis, Vol. 40, No. 2, 1996, pp. 261-274.

[15] W. Luczak, "Zrobotyzowana US Army XXI wieku", ReportWTO, No. 9, 2009.

[16] J. M. Brzezina., Z. Danko, "Wykorzystanie bezzałogowych środków powietrznych w konfliktach zbrojnych", Przegląd Wojsk Lądowych, No. 2, 2005.

[17] M. De Landa, "War in the Age of Intelligent Machines", Swerve Editions, New York, 1991, p. 170. 